\title{
Caracterização botânica e química de Rudgea viburnoides (Cham.) Benth., (Rubiaceae)
}

\author{
Alves, R.M.S. ${ }^{1}$; Stehmann, J.R.. ${ }^{2}$ Isaias, R.M.S. ${ }^{2 \star}$; Brandão, M.G.L. ${ }^{1}$ \\ ${ }^{1}$ Laboratório de Farmacognosia, Faculdade de Farmácia; ${ }^{2}$ Departamento de Botânica, \\ Instituto de Ciências Biológicas, Universidade Federal de Minas Gerais, Belo Horizonte, MG.
}

Recebido para publicação em: 07/10/2003 Aceito para publicação em: 26/01/2004

\begin{abstract}
RESUMO: Congonha, congonha-de-bugre e bugre são nomes populares atribuídos a várias espécies medicinais, incluindo Rudgea viburnoides (Cham.) Benth. (Rubiaceae), cujas folhas são utilizadas na medicina popular como diuréticas, hipotensoras, antireumáticas e depurativas do sangue. Esta espécie vem sendo comercializada como porangaba e utilizada em regimes de emagrecimento, substituindo Cordia ecalyculata Vell. (Boraginaceae). Neste estudo, foram determinadas as características botânicas, fisico-químicas e químicas para $R$. viburnoides com o objetivo de auxiliar sua identificação taxonômica e o controle de qualidade de produtos preparados com esta planta. Uma amostra referência foi coletada e submetida à caracterização macroscópica, microscópica e organoléptica, determinação de cinzas totais e umidade, prospecção fitoquímica e determinação dos perfis cromatográficos em CCD. Amostras de $R$. viburnoides podem ser reconhecidas pela epiderme pilosa com marcantes estrias cuticulares, estômatos paracíticos, presença de idioblastos com ráfides no mesofilo e pela configuração em arco dos tecidos vasculares da nervura de primeira ordem, caracteres ausentes em $C$. ecalyculata. A presença de cistólitos e canais mucilaginosos na medula diferem prontamente $C$. ecalyculata de $R$. viburnoides. A análise por CCD evidenciou a presença de flavonóides e saponinas. Amostras adquiridas no comércio e submetidas aos mesmos ensaios permitiram validar os métodos propostos e confirmaram a ampla comercialização de $R$. viburnoides em Minas Gerais.
\end{abstract}

Unitermos: Rudgea viburnoides; congonha; bugre; porangaba; características botânicas, físico-químicas e químicas.

ABSTRACT: Morphological and chemical diagnosis of Rudgea viburnoides (Cham.) Benth., (Rubiaceae). Congonha, congonha-de-bugre and bugreare popular names for several medicinal plant species, including Rudgea viburnoides (Cham.) Benth. (Rubiaceae), whose leaves are widely used in popular medicine as diuretic, hypotensive, antirheumatic, and blood depurative. This species has been commercialized as porangaba, and used for diet purposes in substitution of Cordia ecalyculata Vell. (Boraginaceae). This study determines botanical, physico-chemical and chemical characteristics of $R$. viburnoides with the objective of providing tools for its taxonomical identification and the quality control of derived products. A reference sample was collected and submitted to macroscopical, microscopical and organoleptical characterization, total ash and water content, phytochemical screening, and TLC profile determination. Samples 
of Rudgea viburnoides can be easily distinguished from those of Cordia ecalyculataby the pilose epidermis with paracytic stomata, outstanding cuticularized striation, the presence of cristalliferous idioblasts, and by the arc pattern of the midvein vascular tissues. Furthermore, $C$. ecalyculata presents cystoliths and medullary mucilaginous channels differing from $R$. viburnoides. TLC analysis demostrated the presence of flavonoids and saponins. Commercially acquired samples submitted to the same assays have therefore validated the proposed methods, and confirmed the wide commercialization of $R$. viburnoides in the state of Minas Gerais, Brazil.

Key words: Rudgea viburnoides; congonha; bugre; porangaba; botanical, physico-chemical and chemical characteristics.

\section{INTRODUÇÃO}

Congonha, congonha-de-bugre ou bugre são nomes populares atribuídos a várias espécies das famílias Aquifoliaceae, Boraginaceae, Ochnaceae, Rubiaceae, Symplocaceae e Icacinaceae (CORRÊA, 1984). Na 1a Edição da Farmacopéia Brasileira (FARMACOPÉIA BRASILEIRA, 1929), Casearia sylvestris Swartz (Flacourtiaceae) encontra-se inscrita como herva de bugre. Em Minas Gerais, este nome popular, além de "bugre" ou "cotó-cotó", aplica-se também à Rudgea viburnoides (Cham.) Benth, uma espécie bastante comum na região do Cerrado. As raízes e cascas desta espécie são utilizadas na medicina popular como diuréticas, hipotensoras, antireumáticas e depurativas do sangue (BALBACH, 1980; SIQUEIRA, 1981; VIEIRA; MARTINS, 2000). Mais recentemente, as folhas desta espécie tornaram-se alvo de extensa comercialização, recebendo o nome de porangaba e sendo indicadas em regimes de emagrecimento.

Saito e Oliveira (1986) caracterizaram botânica e quimicamente Cordia ecalyculata Vell. (Boraginaceae), espécie também conhecida como chá-de-bugre e porangaba. Nesse estudo, os autores já relatavam que a espécie poderia ser confundida com outras, entre elas $R$. viburnoides. No entanto, estudos caracterizando farmacognosticamente as espécies do gênero Rudgea são escassos. Apenas a anatomia foliar de $R$. decipiens e $R$. macrophylla foi detalhadamente descrita (MANTOVANI et al., 1995). Este estudo teve como objetivo a determinação de algumas características farmacognósticas das folhas de $R$. viburnoides, de modo a auxiliar na identificação taxonômica e no controle de qualidade de produtos com elas preparados.

\section{MATERIAL E MÉTODOS}

\section{Material botânico}

Ramos vegetativos e floridos de Rudgea viburnoides foram coletados no município de Nova Lima, MG. Para a ilustração da espécie, utilizou-se como referência a exsicata J.F. Macedo s.n. (BHCB 28194), depositada no herbário do Departamento de Botânica da Universidade Federal de Minas Gerais. Folhas maduras totalmente expandidas foram fixadas e estocadas em FAA (formalina: ácido acético: etanol 50 GL - 1:1:18 - v/v) (JOHANSEN, 1940).

Amostras de drogas vegetais, comercializadas com os nomes populares de congonha, congonha-de-bugre e bugre, foram adquiridas em ervanarias. Foram analisadas 11 amostras, provenientes do Mercado Central de Belo Horizonte (9), Mercado de Curvelo (1) e feira de Sete Lagoas (1). As amostras não continham números de lotes.

\section{Caracterização macroscópica}

As caracterizações macroscópicas dos ramos, folhas e flores foram feitas por meio de observações diretas e com auxílio de estereomicroscópio binocular. 


\section{Caracterização microscópica}

Para os estudos anatômicos, fragmentos foliares com cerca de $1 \mathrm{~cm}^{2}$ do terço médio, bordo e da nervura de primeira ordem em suas porções apical, mediana e basal foram seccionados transversalmente à mão livre, clarificados com hipoclorito $50 \%$ e corados pela mistura azul de astra e safranina 0,5\% (8:2) (KRAUS; ARDUIN, 1997). A epiderme foi destacada de fragmentos foliares do terço médio pelo método de Jeffrey (BERLYN; MIKSCHE, 1976) e coradas em safranina hidroalcoólica 5\% (JOHANSEN, 1940). Todas as lâminas foram montadas em gelatina glicerinada de Kaiser (KRAUS; ARDUIN, 1997). A observação microscópica das drogas pulverizadas foi realizada por meio da observação de pequenas frações das amostras.

\section{Caracterização organoléptica}

Foram observados os aspectos relacionados à cor, odor, sabor e textura de cada amostra (WHO, 1998; FARMACOPÉIA BRASILEIRA, 2000).

\section{Determinação do teor de cinzas totais}

Foi utilizado o método farmacopéico (FARMACOPÉIA BRASILEIRA, 2000). As amostras foram analisadas em triplicata.

\section{Prospecção fitoquímica e determinação do perfil cromatográfico por CCD}

Foram efetuados testes químicos para verificar a presença de flavonóides, taninos, alcalóides, triterpenos, esteróis e saponinas (ALICE et al., 1995).

Foram determinados perfis cromatográficos para flavonóides e saponinas por $C C D$, usando gel de sílica como fase fixa. Utilizou-se os eluentes e reveladores indicados por Wagner e Bladt (1996), ou seja, para flavonóides acetato de etila:ácido fórmico:ácido acético:água (100:13:13:26) e revelação com NP/PEG seguida de observação no UV, e para saponinas clorofórmio:ácido acético:metanol:água (60:32:12:8) e revelação com anisaldeído/ácido sulfúrico, seguida de aquecimento e observação na luz visível.

\section{RESULTADOS E DISCUSSÃO}

\section{Caracterização macroscópica}

A Figura 1 apresenta um ramo florido de $R$. viburnoides. Os ramos jovens apresentam ramificações dicotômicas e são longitudinalmente estriados, de coloração geralmente castanha. $O$ pecíolo é tomentoso, com 3,5-7 mm de comprimento. As folhas são simples, opostas, com estípulas interpeciolares fimbriadas; a lâmina possui 5-13,5 cm de comprimento e 2,5-7,5 cm de largura, forma elíptica, oblonga, ovada ou obovada, ápice obtuso ou arredondado, às vezes, emarginado, base obtusa ou arredondada, mais raramente aguda; a textura é coriácea e a margem revoluta; a superfície adaxial apresenta coloração escura ao secar, especialmente as folhas novas, e é glabra, com as nervuras imersas no limbo; a superfície abaxial é pardacenta, tomentosa a subvilosa, com nervuras de primeira ordem e de segunda ordem espessadas, proeminentes e de coloração mais clara em relação ao limbo; a venação é broquidódroma, com nervuras de terceira ordem ortogonais reticuladas. A inflorescência é terminal, multiflora, tirsóide, com 4-10 cm de comprimento, com pedúnculo de 1,5-5 $\mathrm{cm}$ de comprimento. As flores são diclamídeas, pentâmeras, epigínicas, dicogâmicas, de dois tipos: longi e brevistilas. O cálice é verde e a corola é branca, tubulosa, com tubo de 3-3,5 mm de comprimento, 
internamente glabro na base e com um anel de tricomas no ápice, externamente piloso; os lobos da corola possuem 4-5 $\mathrm{mm}$ de comprimento e são elíptico-lanceolados. Os estames são em número de 5, epipétalos, e estão adnatos à corola em quase toda a extensão do tubo, sendo livres apenas 3-3,5 $\mathrm{mm}$; as anteras têm cerca de $2 \mathrm{~mm}$ de comprimento. $\mathrm{O}$ ovário é ínfero, bicarpelar, bilocular e cada lóculo possui apenas 1 óvulo; o estilete é glabro, filiforme, com 3,5 $\mathrm{mm}$ de comprimento e o estigma é bífido, cada ramo com cerca de $1 \mathrm{~mm}$ de comprimento. Os frutos e sementes não foram observados.

Pela morfologia externa, esta espécie pode ser facilmente diferenciada de Cordia ecalyculata (Boraginaceae). Enquanto R. viburnoides apresenta folhas opostas, geralmente ovadas a elipticas, ápice obtuso ou arrendondado, com margem revoluta, coriáceas, face abaxial tomentosa a subvilosa, bem como estípulas interpeciolares, $C$. ecalyculata possui folhas alternas, lanceoladas ou oblongo-lanceoladas, ápice agudo, planas, membranáceas, glabras e estípulas ausentes (SAITO; OLIVEIRA, 1986).

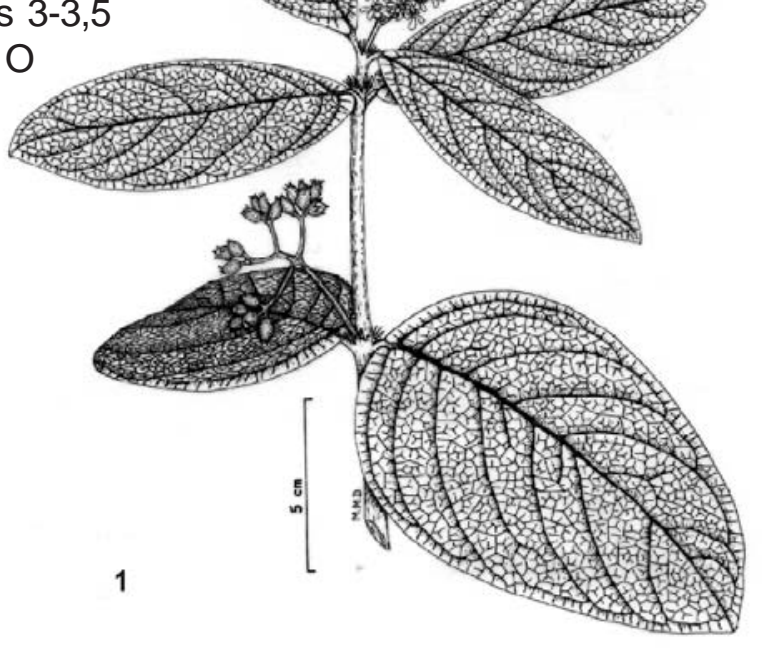

Figura 1. Rudgea viburnoides (Cham.) Benth. (Rubiaceae) - ramo florido

\section{Caracterização microscópica}

\section{Anatomia da folha}

A epiderme da face adaxial em vista frontal apresenta células com paredes anticlinais retilíneas levemente arqueadas, encobertas por cêras epicuticulares (Figura 2). Em secção transversal, observam-se 1-2 estratos com células de seção transversal quadrangular e paredes periclinais externas espessadas, revestidas por cutícula espessa. A lâmina foliar, em secção transversal, mostra-se tipicamente dorsiventral, hipostomática e pilosa na face abaxial (Figura 4). Os tricomas são tectores, pluricelulares, unisseriados, sendo constituídos por quatro células alongadas. A presença de tricomas é um caráter que diferencia $R$. viburnoides de $R$. decipiens e $R$. macrophylla, ambas descritas por Mantovani et al. (1995) como glabras. Na face abaxial, a epiderme em vista frontal apresenta numerosos estômatos paracíticos (Figura 3) e tricomas. Em secção transversal, observam-se células de seção transversal arredondada e de menores dimensões que aquelas da face adaxial, revestidas por cutícula delgada (Figura 4).

O parênquima clorofiliano paliçádico é formado por um estrato de células que ocupa aproximadamente $1 / 3$ da espessura do mesofilo. O parênquima clorofiliano lacunoso é formado por 7-8 estratos de células em meio às quais distinguem-se pequenos feixes vasculares colaterais. Estes pequenos feixes acham-se envolvidos por uma bainha tipicamente parenquimática (Figura $5)$. As características gerais do parênquima clorofiliano de $R$. viburnoides são similares àquelas de $R$. decipiens e $R$. macrophylla (MANTOVANI et al. 1995), sendo o número de camadas do parênquima clorofiliano lacunoso um caráter variável entre as espécies. Por se tratar de um caráter muito variável, capaz de responder às condições ambientais (MAUSETH, 1988; FAHN, 1990; DICKISON, 2000), não deve ser considerado para diagnóstico entre espécies.

O bordo foliar é revestido por epiderme unisseriada cujas células têm paredes periclinais marcadamente convexas na porção distal. O sistema fundamental do bordo é constituído por 3-4 camadas de colênquima (Figura 6), similar ao descrito para R. macrophylla (MANTOVANI et al. 1995). Tricomas podem estar presentes nesta região. Na região proximal do bordo, distinguem-se dois feixes

Rev. Bras. Farmacogn., V. 14, n. 1, jan.-jun. 2004. 
vasculares colaterais de dimensões distintas com xilema e floema pouco desenvolvidos e células lignificadas dispostas entre o xilema e o floema e nas porções adaxial e abaxial do feixe (Figura 7).

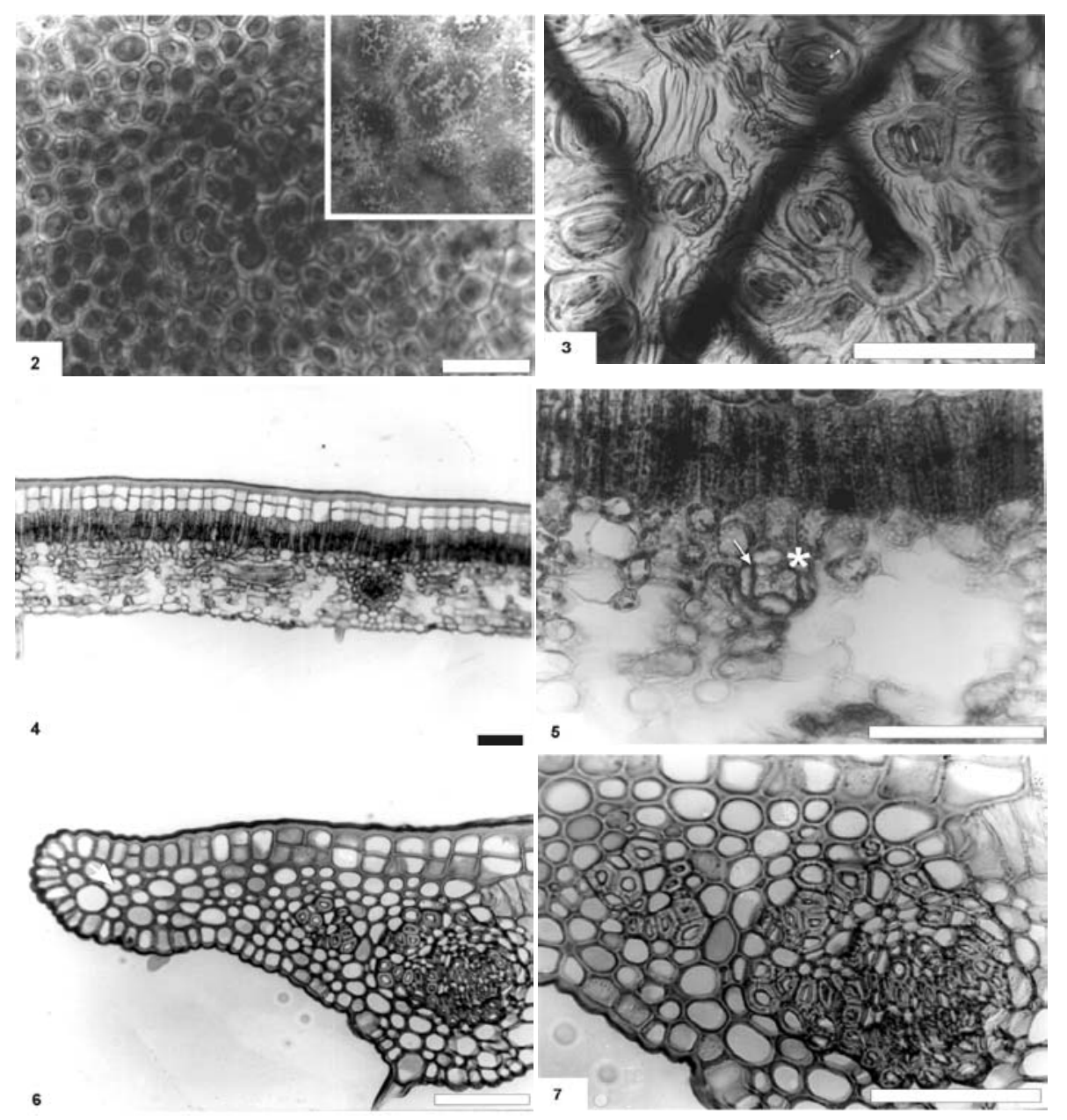

Figura 2-7. Rudgea viburnoides - Epiderme e lâmina foliar. (2) Epiderme da face adaxial em vista frontal evidenciando as paredes celulares anticlinais retilíneas, encobertas pela cêra epicuticular (em detalhe). (3) Epiderme da face abaxial em vista frontal evidenciando estrias cuticulares, estômatos paracíticos e base de tricoma tector. (4) Aspecto geral da lâmina foliar em secção transversal. (5) Detalhe de nervuras de menor ordem imersa no parênquima lacunoso envolvida por bainha parenquimática. (6) Bordo foliar em seção transversal evidenciando colênquima e bases de tricomas. (7) Feixes vasculares proximais ao bordo onde células lignificadas localizam-se entre os tecidos vasculares (barra $=50 \mu \mathrm{m}$ ).

No ápice foliar, na região da nervura de primeira ordem, a epiderme apresenta-se unisseriada com células alongadas no sentido anticlinal. Na face abaxial, as células epidérmicas apresentam paredes periclinais externas marcadamente papilosas. Tricomas tectores estão presentes nesta face. A região adjacente à epiderme adaxial é ocupada por 2 estratos de colênquima e 1-2 estratos de parênquima fundamental. Na face adaxial, o parênquima cortical apresenta 8-9 estratos celulares. O sistema vascular apresenta características de crescimento secundário, com xilema e floema em arranjo colateral envolvidos por fibras pericíclicas formando um anel (Figura 8).

No terço médio, na nervura da primeira ordem, a epiderme apresenta-se unisseriada de dimensões menores que aquelas da região internervural, tanto na face adaxial quanto na abaxial. $\mathrm{Na}$ face adaxial, a região adjacente à epiderme é ocupada por 4-5 estratos de colênquima. A região adjacente à epiderme abaxial, sobre a nervura primeira ordem, é constituída por 3 camadas de colênquima angular. O parênquima fundamental é mais desenvolvido nesta face, sendo constituído por células arredondadas quanto vistas em seção transversal. O sistema vascular apresenta características de 
crescimento secundário com o xilema mais desenvolvido que o floema, arranjo colateral e disposição em arco. Todo o conjunto acha-se envolvido por fibras pericíclicas em anel contínuo (Figura 9). Na face abaxial, a epiderme apresenta as paredes periclinais externas marcadamente papilosas. Tricomas tectores estão presentes nesta face. Mantovani et al. (1995) descrevem o sistema vascular de $R$. macrophylla, destacando a disposição do floema em torno de toda a porção xilemática. Pelas descrições apresentadas, $R$. viburnoides apresenta maiores similaridades com $R$. decipiens, onde o sistema vascular também tem arranjo colateral e acha-se envolto por fibras pericíclicas. As nervuras de segunda ordem apresentam feixes vasculares de arranjo colateral com xilema e floema em quantidades equivalentes e envolvido por fibras pericíclicas. O parênquima paliçádico é contínuo sobre estas nervuras, ocupando a face adaxial. A face abaxial é constituída por parênquima fundamental com células de seção transversal arredondada. Na região basal da folha, o sistema vascular da nervura de primeira ordem apresenta-se mais desenvolvido do que no terço médio. Contudo, as fibras pericíclicas proximais ao floema são menos numerosas. Nota-se externamente a estas células, principalmente na face abaxial a presença da endoderme com células de paredes mais delgadas (Figura 10). O parênquima fundamental é bastante desenvolvido nesta região com células em seção transversal com forma arredondada que delimitam pequenos espaços intercelulares. Idioblastos cristalíferos contendo ráfides, que ocupam toda a célula, estão presentes (Figura 12). Estes idioblastos são similares àqueles descritos para $R$. decipiens e $R$. macrophylla (MANTOVANI et al., 1995). Tricomas tectores pluricelulares, unisseriados de comprimentos variados acham-se concentrados na face abaxial da epiderme, sobre a nervura primeira ordem (Figura 11).

Pela anatomia, Rudgea viburnoides pode ser facilmente diferenciada de Cordia ecalyculata (Boraginaceae), pela ausência de cistólitos em $R$. viburnoides, caráter apontado como diagnóstico para C. ecalyculata por Saito e Oliveira (1986). Outros caracteres diferenciais entre as duas espécies são a epiderme glabra, onde se destacam os pontos de inserção dos cistólitos, as 3 células anexas aos estômatos e a configuração da nervura de primeira ordem, constituída por 15 feixes vasculares dispostos em círculo em $C$. ecalyculata, a qual apresenta, ainda, canais mucilaginosos na medula (SAITO; OLIVEIRA 1986). Muito embora Saito e Oliveira (1986) não apontem estes caracteres como diagnósticos, podemos concluir que os mesmos diferem prontamente C. ecalyculata de $R$. viburnoides.

\section{Caracterização organoléptica}

As folhas de $R$. viburnoides apresentam coloração verde-acastanhada na face abaxial, sabor levemente amargo e são inodoras.

\section{Determinação do teor de cinzas totais}

O teor de cinzas encontrado variou de $10-11 \%$.

\section{Prospecção fitoquímica e determinação do perfil cromatográfico por CCD}

Os testes químicos apresentaram reação positiva para taninos, flavonóides, triterpenos e saponinas. O perfil cromatográfico para flavonóides apresentou cinco manchas, sendo duas azuis fluorescentes, com valores de $\mathrm{Rf}$ de 0,3 e 0,7, duas laranjas com valores de $\mathrm{Rf}$ de 0,4 e 0,6 e uma amarela com valor de Rf de 0,5, quando reveladas com NP/PEG e observadas em UV. Nenhuma mancha apresentou valores de Rf semelhantes aos da quercetina e rutina, utilizadas como substâncias de referência.

O perfil cromatográfico para saponinas apresentou cinco manchas com valores de Rf de 0,23; 0,36; 0,66; 0,78 e 0,90, através da revelação com anisaldeído/ácido sulfúrico e aquecimento a $100-105^{\circ} \mathrm{C}$, durante 10 minutos. Saponinas e triterpenos já haviam sido detectados nas cascas dos frutos maduros de $R$. viburnoides (YOUNG et al., 1998) e uma saponina apresentou moderada atividade antifúngica contra Cladosporium cladosporioides. 

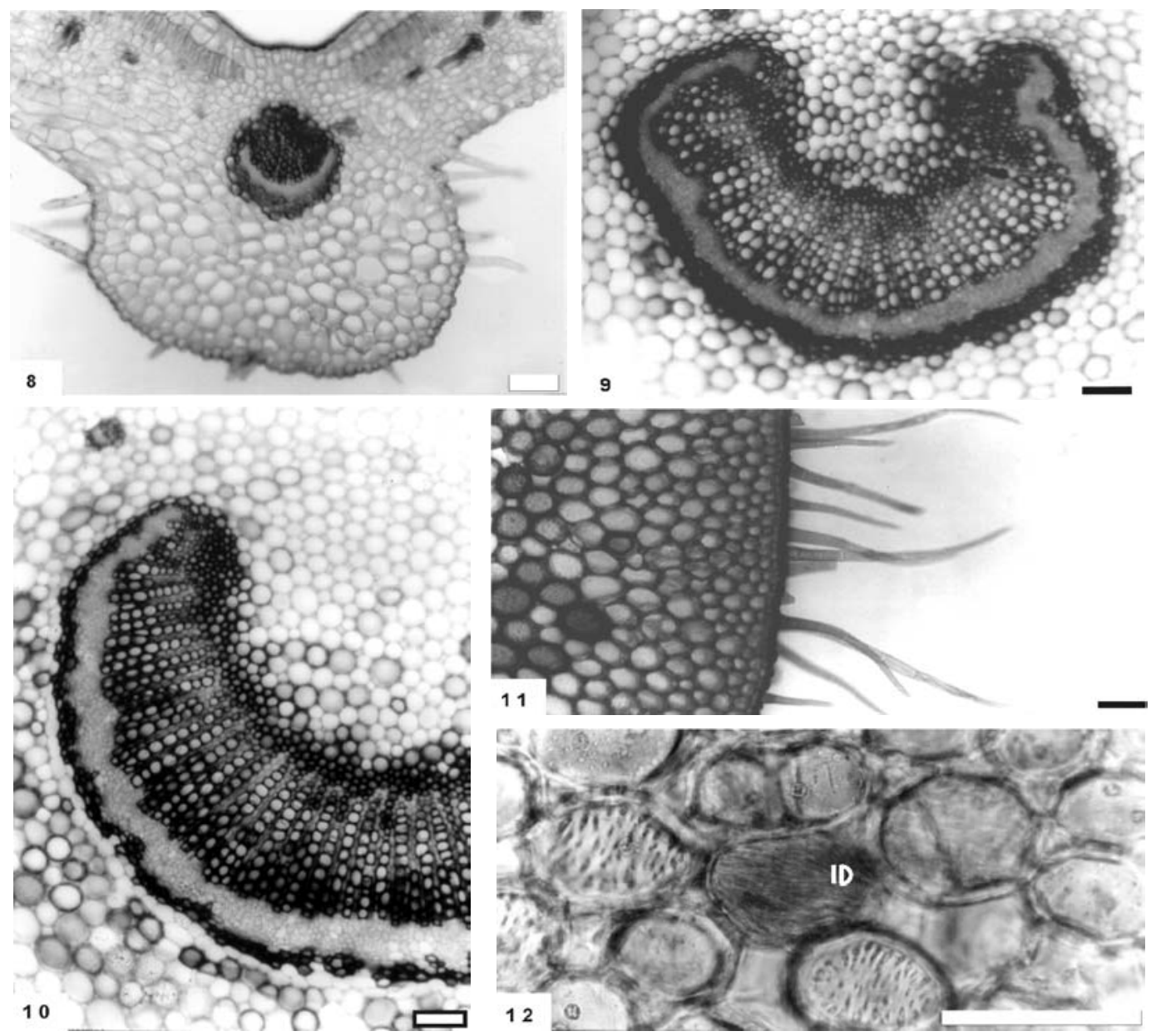

Figura 8-12. Rudgea viburnoides - Região da nervura de primeira ordem. (8) Região apical da folha evidenciando sistema vascular colateral, envolto por um anel de fibras pericíclicas e grande desenvolvimento do sistema fundamental na face abaxial. (9) Sistema vascular na altura do terço médio da lâmina foliar evidenciando maior desenvolvimento do anel de fibras pericíclicas. (10) Sistema vascular na região basal da lâmina foliar onde nota-se maior desenvolvimento do sistema vascular, redução da lignificação do periciclo e presença de endoderme. (11) Detalhe da porção lateral da nervura evidenciando tricomas tectores pluricelulares unisseriados. (12) Detalhe do parênquima cortical evidenciando idioblasto cristalífero contendo ráfides (barras $=50 \mu \mathrm{m}$ ).

Alcalóides são encontrados em diversas espécies medicinais da família Rubiaceae, como ipeca (Psychotria ipecacuanha (Brot.) Stokes), quinas (Cinchona spp) e unha-de-gato (Uncaria tomentosa DC.). Em algumas espécies do gênero Psychotria, eles ocorrem nas folhas e possuem propriedades analgésicas (ELISABETSKY et al., 1997). Nas folhas de Rudgea viburnoides, contudo, não foram detectados alcalóides. Não foi identificada também a alantoína, marcador químico identificado em C. ecalyculata (SAITO et al., 1985).

\section{Amostras comerciais}

Todas as amostras comercializadas como congonha e/ou bugre, adquiridas nas ervanarias de Belo Horizonte corresponderam à $R$. viburnoides. Este quadro parece indicar que a espécie é facilmente reconhecida pelos raizeiros que coletam o material para comercialização. Apesar da uniformidade encontrada nas amostras, as mesmas são comercializadas com nomes e indicações terapêuticas diferentes. 


\section{CONCLUSÃO}

Os dados obtidos permitem estabelecer parâmetros para a identificação botânica e química das folhas de Rudgea viburnoides, diferenciando-a de Cordia ecalyculata. Esses parâmetros devem contribuir diretamente para a análise da qualidade de amostras da planta e de produtos fitoterápicos preparados com a mesma.

\section{REFERÊNCIAS}

ALICE, C.B.; SIQUEIRA, N.C.S.; MENTZ, L.A.; SILVA, G.A.A.B.; JOSÉ, K.F.D. Plantas medicinais de uso popular: atlas farmacognóstico. Canoas: Editora da Ulbra, 1995.

BALBACH, A. A flora nacional na medicina doméstica. 17. ed. São Paulo: EDEL, 1980. V.2.

BERLYN, G.P.; MIKSCHE, J.P. Botanical microtechnique and cytochemistry. Ames: The lowa University Press, 1976.

CORRÊA, M.P. Dicionário das Plantas Úteis do Brasil e das exóticas cultivadas. Rio de Janeiro: Imprensa Nacional, 1984.

DICKISON, W.C. Integrative plant anatomy. San Diego: Academic Press, 2000.

ELISABETSKY, E.; AMADOR, T.A.; LEAL, M.B.; NUNES, D.S.; CARVALHO, A.C.T.; VEROTTA, L. Merging ethnopharmacology with chemotaxonomy: An approach to unveil bioactive natural products. The case of Psychotria alkaloids as potencial analgesics. Ciência e Cultura, v.49, n.5-6, p. 378-385, 1997.

FAHN, A. Plant anatomy. Oxford: Pergamon Press, 1990.

FARMACOPÉIA BRASILEIRA. São Paulo: Companhia Editora Nacional, 1929.

FARMACOPÉIA BRASILEIRA. 4. ed. São Paulo: Atheneu, 2000.

JOHANSEN, J. Plant microtechnique. New York: McGraw-Hill, 1940.

KRAUS, J.; ARDUIN, M. Manual básico de métodos em morfologia vegetal. Seropédica: EDUR, 1997.

MANTOVANI, A.; GOMES, M.; GOMES, D.M.S.; VIEIRA, R.C. Anatomia foliar de Rudgea decipiens Müell. Arg. e R. macrophylla Benth. (Rubiaceae). Acta Botanica Brasilica, v.9, n.2, p.247-261, 1995.

MAUSETH, J. Plant anatomy. Menlo Park: The Benjamin Cummings Pub, 1988. 560p.

SAITO, ML.; OLIVEIRA, F.; ALVARENGA, M.A. Alantoína e outros constituintes químicos de Cordia ecalyculata Vell. Revista de Farmácia e Bioquímica da Universidade de São Paulo, v.21, n.1, p.14-19, 1985.

SAITO, M.L.; OLIVEIRA, F. Morfodiagnose e identificação cromatográfica em camada delgada de chá de bugre Cordia ecalyculata Vell. Revista Brasileira de Farmácia, v.67, n.1-3, p.1-16, 1986.

SIQUEIRA, J.C. Utilização popular das plantas do Cerrado. São Paulo: Loyola, 1981.

VIEIRA, R,F., MARTINS, M.V.M. Recursos genéticos de plantas medicinais do Cerrado: uma compilação de dados. Revista Brasileira de Plantas Medicinais, v. 3, n. 1, p. 13-36, 2000.

WAGNER, H.; BLADT, S. Plant Drug Analysis. Berlin: Springer, 1996.

WHO. Quality control methods for medicinal plant materials. Geneva: World Health Organization, 1998.

YOUNG, M.C.; ARAUJO, A.F.; DASILVA, C.A.; LOPES, M.N.;TREVISAN, L.M.; BOLZANI, V.S. Triterpenes and saponins from Rudgea viburnoides. Journal of Natural Products, v.61, p.936-938, 1998.

*Autor para correspondência:

Profa. Dra. Rosy Mary dos Santos Isaias

Departamento de Botânica

Instituto de Ciências Biológicas

Universidade Federal de Minas Gerais

Av. Antônio Carlos, 6627

31270-110 - Belo Horizonte, MG

E-mail: rosymary@dedalus.lcc.ufmg.br

Rev. Bras. Farmacogn., V. 14, n. 1, jan.-jun. 2004. 